\title{
Corrective Measures for the Effective Load Management and Control Under Disturbance at Bhusawal Thermal Power Station: Case Study
}

\author{
Makarand Sudhakar Ballal • Deepali Makarand Ballal • \\ Hiralal Murlidhar Suryawanshi • Mahesh Kumar Mishra
}

Received: 4 December 2012 / Accepted: 28 April 2014/Published online: 29 May 2014

(C) The Institution of Engineers (India) 2014

\begin{abstract}
A modern power grid needs to become smarter in order to provide an affordable, reliable, and sustainable supply of electricity. The objective of this work is to investigate the discrepancies in power flow control under the abnormal circumstances and to maintain grid stability. This paper reports investigation into the factors that influence the dynamic behavior of the power control from Bhusawal Thermal Power Station (BTPS), India. The problems of existing power system are discussed by considering the case studies of BTPS substation and very efficient solutions are proposed to resolves these hurdles. Load flow studies are carried out for different cases, considering realistic load condition before and after disturbances. Simulation is performed in MATLAB environment and recorded parameters are compared with simulation results.
\end{abstract}

M. S. Ballal $(\bowtie) \cdot$ H. M. Suryawanshi

Visvesvaraya National Institute of Technology, Nagpur,

Nagpur 440010, Maharashtra, India

e-mail: msb_ngp@rediffmail.com

H. M. Suryawanshi

e-mail: hms_1963@rediffmail.com

\section{M. Ballal}

Extra High Voltage Division, Maharashtra State Electricity

Transmission Company Limited, Nagpur, Nagpur 440033,

Maharashtra, India

e-mail: deepaliballal@ rediffmail.com

M. K. Mishra

Indian Institute of Technology, Madras, Chennai 600036,

Tamilnadu, India

e-mail: mahesh@ee.iitm.ac.in
Keywords Generating unit (GU) .

Bhusawal Thermal Power Station (BTPS) .

Load Trimming Scheme (LTS) · Multistage relay •

Load flow study $\cdot$ MATLAB Simulink

\section{Introduction}

An electrical power grid is a critical infrastructure, whose reliable, robust, and efficient operation greatly affects national economics, politics, and people's everyday life. Power grid crises, which have frequently taken place at world, alert the importance of power grid crises management. With the development of interconnection of big power grid, a small-disturbance stability of a power system should not be ignored. Grid applications access distributed, and often shared resources. One consequence of this resource sharing is that measured application performance can vary widely and in unexpected ways. To respond to changing execution conditions, applications and grid systems must be nimble and adaptive.

The analytical basis for an application of slow coherency theory to the design of an islanding scheme discussed in the literature [1], employed as an important part of a corrective control strategy to deal with large disturbances. Investigations about pre-planned switching events and fault events explained in the article [2], lead to islanding of a distribution subsystem and formation of a micro grid. The studies show that an appropriate control strategy for the power electronically interfaced distributed generation (DG) unit can ensure stability of the micro grid and maintain voltage quality at designated buses, even during islanding transients. A three-phase four-wire grid-interfacing power quality compensator for micro grid applications is presented in the article [3]. The compensator is proposed for 
use with each individual DG system in the micro grid and consists of two four-phase-leg inverters (a shunt and a series), optimally controlled to achieve an enhancement of both the quality of power within the micro grid and the quality of currents flowing between the micro grid and the utility system.

A grid interfacing power quality compensator for threephase three-wire micro grid applications with consideration of both the power quality of the micro grid and the quality of currents flowing between the micro grid and utility system is explained by the authors [4]. The case examined in [5] is a power park of several inverter based DG in relatively close proximity. In small grids with high proportion of nonlinear and unbalanced loads, it is also important to actively control the waveform quality in terms of harmonics, transient disturbances, and balance. A flexible active power control based on a fast current controller and a reconfigurable reference current selector is proposed in the literature [6], whereas, the power flow control problem of a grid connected inverter in DG applications is given in the article [7]. A real and reactive power control solution is proposed on the basis of an existing voltage control strategy developed for island operations. A power system frequency control strategy is designed [8], which is mainly used to improve the stability of the islanding power system. The balanceable power before disturbance and the capacity of the removed power can be used to calculate the power deficiency. Then, appropriate load can be shed adaptively. A four-leg shunt multifunctional grid connected power quality compensator is mentioned in the literature [9]. The compensator reference currents are generated using the instantaneous $p-q-r$ theory. A digital controller is used to implement dead-beat current control. The dynamic models in MATLAB Simulink which investigates the behavior of doubly fed induction generator during unbalanced grid voltage condition is explained [10], and provides information about controllers in separated positive and negative sequence.

Large signal transient load model to represent the composite power electronic load at a network bus is explained in the article [11]. Traditional load models do not account for the transient responses of power electronic loads which occur at the onset and clearing of voltage sags. In order to design an efficient communication scheme and examine the efficiency of any networked control architecture in smart grid applications, we need to characterize statistically its information source, namely the power grid itself. Study of both the topological and electrical characteristics of power grid networks based on a number of synthetic and real world power systems are discussed in the literature [12]. A three step control methodology is proposed [13] to manage the cooperation between these technologies like DG, distributed storage, and demand side load management, focused on domestic energy streams. Here, using good predictions, in advance planning and real time control of domestic appliances, a better matching of demand and supply can be achieved.

A modern power grid needs to become smarter in order to provide an affordable, reliable, and sustainable supply of electricity. A vision for the future of smart transmission grids in which their major features are identified [14] that functionally consists of three interactive, smart components, i.e., smart control centers, smart transmission networks, and smart substations. Vision of next generation monitoring, analysis, and control functions for tomorrow's smart power system control centers is discussed by some authors [15]. The present control center technology and the vision of the next generation monitoring, analysis, and control functions are also presented. The implementation of highly realistic real time, massive, online, multi time frame simulations is proposed [16] as a means for building a common vision of smart grid functions among politicians, regulators, managers, operators, engineers, and technicians. An expert operator decision model is described with a view to helping system developers build operator centered and friendly smart grid control systems.

A dc coupled wind/hydrogen/super capacitor hybrid power system is studied in the paper [17]. The purpose of the control system is to coordinate these different sources, particularly their power exchange, in order to make controllable the generated power. An intelligent load shedding algorithm for intentional islanding and an algorithm of synchronization for grid reconnection are explained [18]. A control strategy which utilizes an internal oscillator to maintain the island frequency and a feedback control system to regulate the island voltage for the autonomous (islanded) operation of a four wire, electronically coupled DG unit which can feed a highly unbalanced load is described by the authors [19]. This control strategy provides a set of balanced three phase voltages for the load, despite the load imbalance and parameters uncertainties. To strengthen the small disturbance research can effectively prevent the occurrence of the power grid crises.

This article considered the realistic problem of grid crisis in respect of $132 \mathrm{kV}$ Bhusawal Thermal Power Station (BTPS), India, related to deficiency in generation at any time. It is intended that the power demand should fulfill with quality and reliability and the distribution companies started to collect quality and reliability charges from certain bulk consumers. After restructuring of power system, the issue related to supply and demand become more crucial as the existing power industries have still old generating units (GUs) and old transmission lines. It is observed and recorded under many conditions that the old power plants are about 50 years old and need replacement on priority. These old GUs are suffering due to various 
problems. The more common problems are old auxiliaries, boiler tube leakages, poor coal quality, etc. These old GUs are therefore become more unreliable and it is definitely not advisable to depend upon their generations. State already facing problem of power deficiency as about 12 hours load shading is to be performed eventually due to power shortage. Also, the performance of old GUs is unreliable and it makes the situation more critical. In the State, the old GUs are working at Bhusawal, Parali, Nasik, Koradi, etc. and their total generating capacity is about $340 \mathrm{MW}$. It is always found difficult to rely on these GUs as they can be seldom taken out from the system. Like the old GUs of power plant, the power transmission lines are also become old as they are commissioned about forty to fifty years back. The capacity of power transmission is also required to enhance due to increase in power demand. Most of the lines are of 0.2 aluminum conductor steel reinforced (ACSR) panther conductor and they can carry current up to $482 \mathrm{~A}$ at $45{ }^{\circ} \mathrm{C}$. However, it is observed in practice that these conductors carrying current more than $500 \mathrm{~A}$. Therefore, it also came into notice that, the old lines having inadequate power transmission capacity deals problems because of broken conductor, snapping of conductor, etc. These old GUs and lines are responsible to restrict reliable power supply to consumers. Thus, the existing power system is striving under the constraints of old GU's and power transmission lines. Bhusawal Thermal Power Station is one of such example of this kind of problems. The limitations of this power plant and transmission related problems are reported in this article. The emphasis of this paper is to analyze the existing problem at BTPS along with case study and to propose solutions to overcome this problem. For this purpose, load flow analyses have been made in MATLAB Simulink and the simulation results are compared with the actual recorded values.

\section{Existing Load Flow Scenario of BTPS System}

The power generation capacity of BTPS is $210 \mathrm{MW} \times$ $2+62.5 \times 1$ i.e. $482.5 \mathrm{MW}$. It is seen from the single line diagram of BTPS switchyard illustrated in Fig. 1 that the $132 \mathrm{kV}$ bus has two sections named as Grid Control Room (GCR) switch yard and Electrical Control Room (ECR) switch yard and these switch yards are connected by bus sectionalizer circuit breaker called as interconnector 1 and 2. The ECR section has one generator of $62.5 \mathrm{MW}, 132 /$ $33 \mathrm{kV}$ transformers of $2 \times 25 \mathrm{MVA}, 132 / 6.6 \mathrm{kV}$ station transformer of $1 \times 10$ MVA, $132 / 25 \mathrm{kV}$ Railway Transformer of 20 MVA and 132/11 kV distribution transformer $16 \mathrm{MVA}$, along with five numbers of $33 \mathrm{kV}$ feeders. There is no grid feeder connected to this section. This section gets connected to grid only through interconnector 1 and 2 circuit breaker. The GCR section consists of $2 \times 210 \mathrm{MW}$ generator units, five grid feeders and four radial feeders. Grid feeders were indicated by arrows in both directions; however, radial feeders were indicated by arrows in one direction. These generating sets are about fifty years old and they are suffering due to chronic problems like tube leakages, old inefficient auxiliaries, etc. These days the quality of coal supplied to power station found poor and it hampers the generation. The maintenance of old auxiliaries

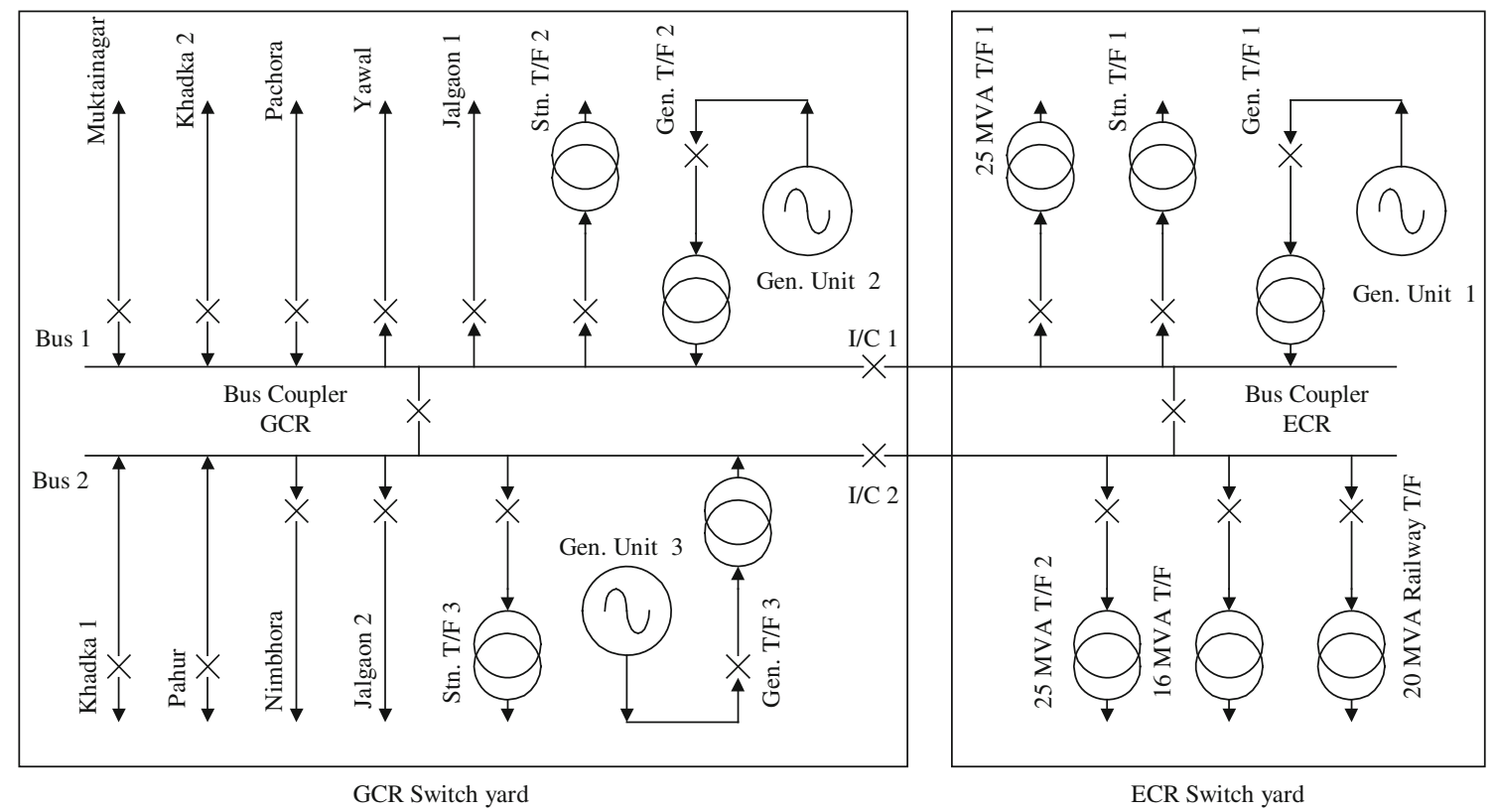

Fig. 1 Single line diagram of BTPS switchyard 
and their unscheduled outages also disturb the production of electricity. Another source to this grid connected substation is from $400 \mathrm{kV}$ receiving station, Khadka. In case of complete dark out, the source is always fed from this Khadka receiving station. Two circuits of $132 \mathrm{kV}$ level are connected from Khadka end to BTPS bus and the current carrying capacity of each of the circuit consisting of 0.4 ACSR Deer conductor is $806 \mathrm{~A}$ at ambient temperature of $40{ }^{\circ} \mathrm{C}$. The remaining feeders are either grid connected or radial type consist of 0.2 ACSR Panther conductor and have current carrying capacity of $520 \mathrm{~A}$ at $40{ }^{\circ} \mathrm{C}$. The load fed from BTPS bus is normally 1,800 A and maximum goes up to 2,000 A as observed from the substation log book. There are four radial feeders emerging from this BTPS bus and fed load about 1,100 A under normal condition, other grid feeders except Khadka receiving station always export power from BTPS bus. The normal and maximum power import and export scenario of all the feeders and GUs is tabulated in Table 1. The capacity of power drawl from $400 \mathrm{kV}$ receiving station, Khadka is restricted to $600 \mathrm{~A}$ for each circuit by means of relay settings. The purpose of this Load Trimming Scheme (LTS) provided at is to avoid over loading of ICTs installed at $400 \mathrm{kV}$ receiving station, Khadka and it also limits the excess drawl of power due to conductor constraints. This LTS consist of simple over current relaying circuitry to individual feeder and it provides trip command to all the existing radial feeder simultaneously as each circuit crosses the limit of $600 \mathrm{~A}$ fed from Khadka station. Therefore, all the four radial feeders trip at a glance and provide load relief due to operation of LTS and avoid overloading and maintain the power system safely under limit. The (current transformer) CT Ratio of each feeder is $800 / 1 \mathrm{~A}$ and setting of over current relay of this LTS is $75 \%$, when both the circuits are in service. However, the setting can be enhanced to $100 \%$ when only one circuit is in service. This LTS operated recently four times due to different reasons [20]. All, the four cases are explained in following paragraphs along with load flow study carried out in MATLAB Simulink. To carry the load flow analysis following assumptions have been made [21, 22].

- $132 \mathrm{kV}$ incoming bus bars of BTPS are considered as reference bus.

- Only one transformer is taken into consideration on each ECR side bus which is equivalent to number of transformers on that particular bus.

- Average temperature of transformer is assumed to be $70{ }^{\circ} \mathrm{C}$ and frequency to be $50 \mathrm{~Hz}$.

- Load is assumed to be static load and system is in steady state condition.

- Marginal limit for voltage $98-102 \%$ and critical limit for voltage $95-105 \%$.

\section{Case Studies and Their Load Flow Analysis}

Single line diagram of BTPS, as depicted in Fig. 1, has been considered for the load flow analysis. Computer simulation of the substation has been carried out in MATLAB Simulink for steady state, actual load condition data received from BTPS. Load flow analysis has been made with and without disturbance conditions. Simulation results are then compared with the recorded results of BTPS.

\section{Case 1}

LTS operated at BTPS on February 16, 2011 at 1349 hours, the power flow import and export scenario is as illustrated in Fig. 2a. The GU 2 was in service and unit 1 and 3 were under outage conditions. Unit 2 was importing $700 \mathrm{~A}$ and both the feeders from $400 \mathrm{kV}$ RS Khadka were supplying $500 \mathrm{~A}$ each to BTPS bus. The export power was $150 \mathrm{~A}$ to ECR switch yard including power requirement of station transformer 1, 80 A to station transformer 2 and 3 both,

Table 1 Normal and maximum power import/export at BTPS

\begin{tabular}{llllllllll}
\hline Sl. No. & $\begin{array}{l}\text { Name } \\
\text { of feeder }\end{array}$ & $\begin{array}{l}\text { Normal load } \\
\text { in A }\end{array}$ & $\begin{array}{l}\text { Max. load } \\
\text { in A }\end{array}$ & $\begin{array}{l}\text { Normally import } \\
\text { or export }\end{array}$ & $\begin{array}{l}\text { Sl. No. } \\
\text { feeder }\end{array}$ & $\begin{array}{l}\text { Name of } \\
\text { in A }\end{array}$ & $\begin{array}{l}\text { Max. load load } \\
\text { in A }\end{array}$ & $\begin{array}{l}\text { Normally import } \\
\text { or export }\end{array}$ \\
\hline 1 & GU 1 & 125 & 250 & Import & 9 & M'Nagar & 150 & 250 & Export \\
2 & GU 2 & 700 & 700 & Import & 10 & Pahur & 150 & 250 & Export \\
3 & GU 3 & 700 & 700 & Import & 11 & Pachora & 150 & 250 & Export \\
4 & Station T/F 1 & 30 & 30 & Export & 12 & Jalgaon 1 & 300 & 300 & Export \\
5 & Station T/F 2 & 40 & 40 & Export & 13 & Jalgaon 2 & 300 & 300 & Export \\
6 & Station T/F 3 & 40 & 40 & Export & 14 & Nimbhora & 200 & 300 & Export \\
7 & Khadka 1 & 300 & 800 & Import & 15 & Yawal & 500 & 525 & Export \\
8 & Khadka 2 & 300 & 800 & Import & 16 & ECR & 150 & 250 & Export \\
\hline
\end{tabular}




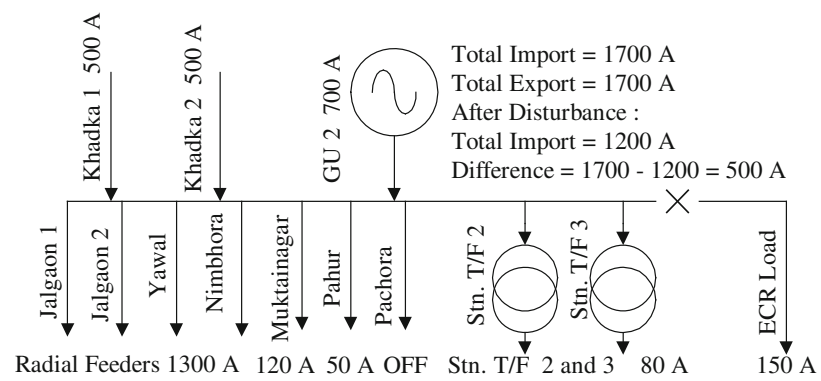

(a)

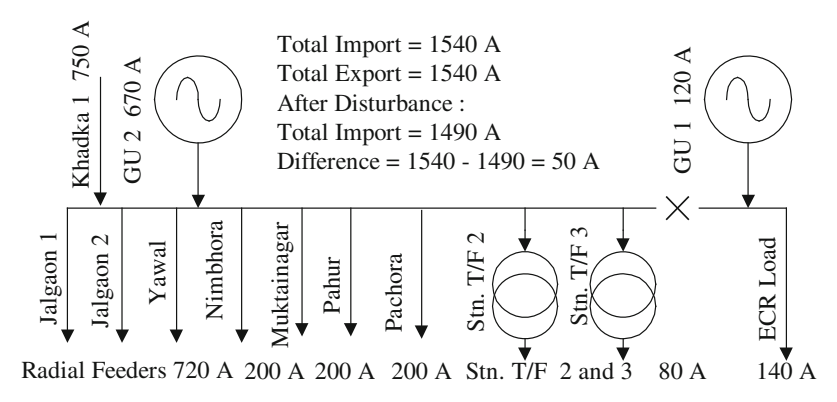

(c)

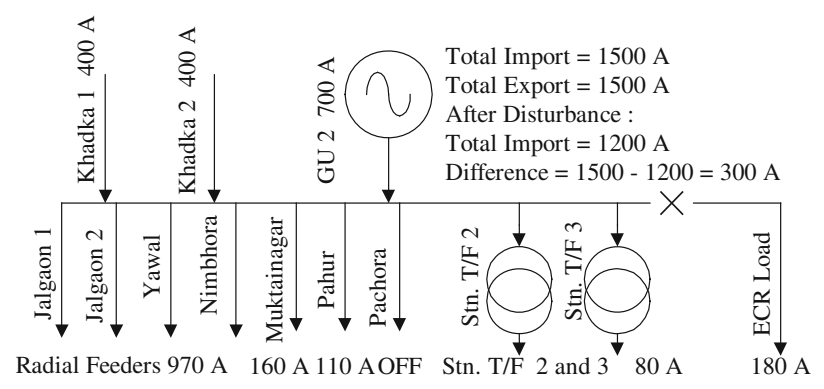

(b)

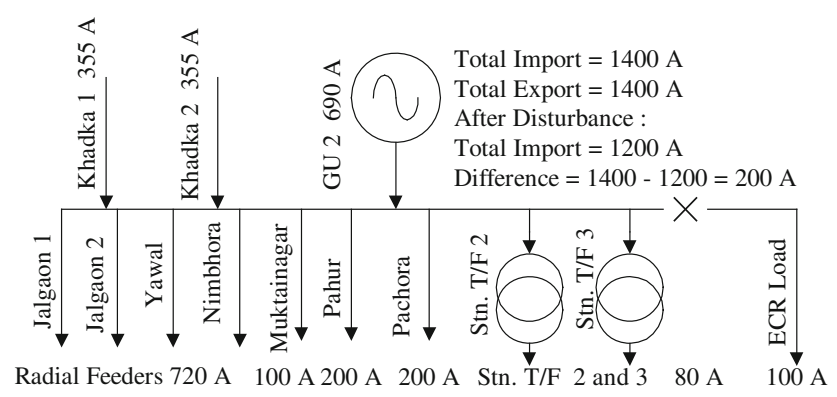

(d)

Fig. 2 Power flow scenario under LTS operation for a case 1, b case 2, c case 3 and $\mathbf{d}$ case 4

120 A to Muktai Nagar circuit, 50 A to Pahur and Pachora circuit was kept off by the instruction from Load Despatcher, Ambazari. At this instant, the total load of all the four radial feeder was about 1,300 A. Generating unit 2 was taken out immediately from the system due to tube leakage problem and hence there was a short fall of $700 \mathrm{~A}$. The setting of LTS over current relay was $75 \%$ as both the lines were in service. As soon as this short fall took place, the import from Khadka RS enhanced to $600 \mathrm{~A}$ for each circuit. But, still there was a short fall of $500 \mathrm{~A}$ and therefore the LTS initiated trip command to the circuit breakers of all the radial feeders. Therefore, for a short fall of $500 \mathrm{~A}$, load curtailed was of 1,300 A. If the settings are kept at $100 \%$, under that condition each circuit could draw $800 \mathrm{~A}$, even after that there will be a short fall of $100 \mathrm{~A}$, and for this small short fall LTS definitely curtail the load of $1,300 \mathrm{~A}$.

\section{Case 2}

LTS operated at BTPS on February 11, 2011 at 1824 hours, the power flow import and export scenario is as illustrated in Fig. 2b. The GU 2 was in service and unit 1 and 3 were under outage conditions. Unit 2 was importing $700 \mathrm{~A}$ and both the feeders from $400 \mathrm{kV}$ RS Khadka were supplying 400 A each to BTPS bus. The export power was 180 A to ECR switch yard including power requirement of station transformer 1, 80 A to station transformer 2 and 3 both,
160 A to Muktai Nagar circuit, 110 A to Pahur and Pachora circuit was kept off by the instruction from Load Despatcher, Ambazari. At this instant, the total load of all the four radial feeder was about $970 \mathrm{~A}$. Generating unit 2 was taken out immediately from the system due to tube leakage problem and hence there was a short fall of $700 \mathrm{~A}$. The setting of LTS over current relay was $75 \%$ as both the lines were in service. As soon as this short fall took place, the import from Khadka RS enhanced to 600 A for each circuit. But, still there was a short fall of $500 \mathrm{~A}$ and therefore the LTS initiated trip command to the circuit breakers of all the radial feeders. Thus, the deficiency of $300 \mathrm{~A}$, load curtailed was of $970 \mathrm{~A}$. If the settings are kept at $100 \%$, under that condition each circuit could draw $800 \mathrm{~A}$, after that there will not be any short fall and thereby there will be no load curtailment.

Case 3

LTS operated at BTPS on December 10, 2010 at 1800 hours, the power flow import and export scenario is as illustrated in Fig. 2c. The unit 1 and unit 3 were in service and unit 2 was under outage conditions. Unit 1 and unit 3 were importing 120 and 670 A respectively. The setting of LTS was raised to $100 \%$ as one the feeder from $400 \mathrm{kV} \mathrm{RS}$ Khadka (Khadka 1) was supplying 750 A and another circuit (Khadka 2) was under outage condition. The export power was 140 A to ECR switch yard including power 
requirement of station transformer $1,80 \mathrm{~A}$ to station transformer 2 and 3 both. The grid feeders Muktai Nagar, Pahur and Pachora circuit each were drawing 200 A from BTPS bus. At this instant, the total load of all the four radial feeder was about 720 A. Generation of Unit 3 was immediately droop down to $570 \mathrm{~A}$ and hence there was a short fall of 50 A only. Hence, LTS initiated trip command to the circuit breakers of all the radial feeders and load curtailed was of $720 \mathrm{~A}$.

\section{Case 4}

LTS operated at BTPS on dated November 12, 2010 at 1600 hours, the power flow import and export scenario is as illustrated in Fig. 2d. The unit 2 was only in service and unit 1 and 3 were under outage conditions. Unit 2 was importing $690 \mathrm{~A}$ and both the feeders from $400 \mathrm{kV}$ RS Khadka were supplying 710 A totally to BTPS bus. The export power was 100 A to ECR switch yard including power requirement of station transformer 1, $80 \mathrm{~A}$ to station transformer 2 and 3 both, 100 A to Muktai Nagar circuit, and $200 \mathrm{~A}$ to Pahur and Pachora circuit each. At this instant, the total load of all the four radial feeder was about 720 A. Generating unit 2 was taken out immediately from the system due to tube leakage problem and hence there was a short fall of $690 \mathrm{~A}$. The setting of LTS over current relay was $75 \%$ as both the lines were in service. As soon as this short fall took place, the import from Khadka RS enhanced to $600 \mathrm{~A}$ for each circuit. But, still there was a short fall of $200 \mathrm{~A}$ and therefore the LTS initiated trip command to the circuit breakers of all the radial feeders. Thus, the deficiency of $200 \mathrm{~A}$, load curtailed was of $720 \mathrm{~A}$. If the settings are kept at $100 \%$, under that condition each circuit could draw $700 \mathrm{~A}$, after that there will not be any short fall and thereby there will be no load curtailment.

The simulation is carried out for all these four cases and their results are compared with the actual recorded data obtained by BTPS meters. The MICON make meter is used for the purpose of monitoring and recording the data. These results are depicted in Table 2. From the above four different cases and their load flow simulation studies, we could reach to opt following remarks.

1. From case 1 and 3 , it came to know that for the deficiency of 100 and 50 A respectively load of the all the radial was curtailed.

2. From case 2 and 4 , it is very well clear that the undesired tripping of LTS protection could be avoid if it's over current the relay was set for $100 \%$.

3. The condition becomes more critical when either one GU or single transmission line is in service.

4. Whenever, there is a generation dip, even though the LTS curtail the load of all four prime radial feeders.

The unreliable generation is the main cause for the operation of LTS and therefore, all the prime important feeders' trip and this badly affect the important bulk consumers and other consumers depends on this feeder connected substations. The problem is in this way formulated and the solution for the effective operation of LTS is considered for the purpose of study in this article. The objective of this paper is to describe the fruitful solution for this problem.

\section{Comprehensive Solution for the Effective Load Flow Control at BTPS}

The prime important substations like $132 \mathrm{kV}$ Jalgaon 1 and Jalgaon 2 are the urban and industrial substations respectively. The power supply to entire Jalgaon urban as well as rural area is from these two substations. These are radial substations and reliable only on BTPS bus supply. Another two substations are $132 \mathrm{kV}$ Yawal and $132 \mathrm{kV}$ Nimbhora. These are rural area substations and entire agriculture load is fed from these two substations. In case of Jalgaon 1 feeder trip from BTPS end, Jalgaon 2 also trip on over current protection and vice versa as these two feeders are parallel and terminate at Jalgaon 1 substation bus. From Jalgaon 1 substation bus another feeder emanates for Jalgaon 2 substation. The Jalgaon 1 and 2 feeders carry load up to 600 A

Table 2 Simulation and recorded results

\begin{tabular}{|c|c|c|c|c|c|c|c|c|c|c|c|c|}
\hline \multirow{3}{*}{$\begin{array}{l}\text { Case } \\
\text { No. }\end{array}$} & \multicolumn{6}{|c|}{ Before disturbance } & \multicolumn{6}{|c|}{ After disturbance } \\
\hline & \multicolumn{3}{|c|}{ Simulation results } & \multicolumn{3}{|c|}{ BTPS meter record } & \multicolumn{3}{|c|}{ Simulation results } & \multicolumn{3}{|c|}{ BTPS meter record } \\
\hline & $\begin{array}{l}\text { Bus voltage } \\
(\mathrm{kV})\end{array}$ & $\begin{array}{l}\mathrm{P} \\
(\mathrm{MW})\end{array}$ & $\begin{array}{l}\text { Q } \\
\text { (MVAR) }\end{array}$ & $\begin{array}{l}\text { Bus voltage } \\
(\mathrm{kV})\end{array}$ & $\begin{array}{l}\mathrm{P} \\
(\mathrm{MW})\end{array}$ & $\begin{array}{l}\text { Q } \\
\text { (MVAR) }\end{array}$ & $\begin{array}{l}\text { Bus voltage } \\
(\mathrm{kV})\end{array}$ & $\begin{array}{l}\mathrm{P} \\
(\mathrm{MW})\end{array}$ & $\begin{array}{l}\text { Q } \\
\text { (MVAR) }\end{array}$ & $\begin{array}{l}\text { Bus voltage } \\
(\mathrm{kV})\end{array}$ & $\begin{array}{l}\mathrm{P} \\
(\mathrm{MW})\end{array}$ & $\begin{array}{l}\text { Q } \\
\text { (MVAR) }\end{array}$ \\
\hline 1 & $132\left\llcorner 0^{\circ}\right.$ & 384 & 62 & 132.4 & 380.7 & 65.1 & $132\left\llcorner 0^{\circ}\right.$ & 96 & 15 & 133.7 & 95.71 & 13.67 \\
\hline 2 & $132\left\llcorner 0^{\circ}\right.$ & 341 & 40 & 131.9 & 344.6 & 39.8 & $132\left\llcorner 0^{\circ}\right.$ & 126 & 13 & 132.9 & 128.9 & 15.4 \\
\hline 3 & $132\left\llcorner 0^{\circ}\right.$ & 348 & 52 & 131.4 & 349.2 & 48.91 & $132\left\llcorner 0^{\circ}\right.$ & 195 & 27 & 132.4 & 192.5 & 29.8 \\
\hline 4 & $132\left\llcorner 0^{\circ}\right.$ & 317 & 43 & 132.1 & 319.9 & 43.65 & $132\left\llcorner 0^{\circ}\right.$ & 160 & 19 & 133.1 & 163.6 & 20.1 \\
\hline
\end{tabular}


consulates, the Yawal feeder carry load up to $500 \mathrm{~A}$ and Nimbora feeder carry load up to $200 \mathrm{~A}$. Therefore, in case LTS relaying protection operates, all the four radial feeders curtailed load of about 1,300 A. The major cause of undesirable operation of LTS protection is either due to unreliable generation of BTPS power plant and inadequate power transmission capacity from nearby substations because of old and 0.2 ACSR conductor. To avoid the undesired blackouts in this specified regional area, it is mandatory to make the generation stable or the short fall of power under such circumstances should be supplied to BTPS bus by any means. The bottleneck between the supply and demand under the circumstance of LTS operation has to be compensated on priority. There are various constraints observed and studied while putting the solution of this problem. Efforts are made in this article to provide comprehensive solution for the effective operation of LTS under the defined constraints. The model for effective LTS relaying scheme is also developed and its simulation results are presented shows the potential of the approach.

\section{Solution 1: Tying of Radial Substations and Load Diversion}

It is come to know from the above discussion that the four important substations are feeding power from only BTPS bus only. Whenever, there is a problem to BTPS bus either due to LTS tripping or due to LBB operation or due to Bus bar protection operated, it will definitely hamper the power import to the bus of these four radial substations. This severely affects all important consumers connected to these substations. If all these four substations tied up with the nearby substations, the entire black out condition due to problem from BTPS side can be avoid to certain extent. These substations should be link for e.g. Jalgaon 1 and 2 can be connected to $132 \mathrm{kV}$ bus of $400 \mathrm{kV}$ RS, Khadka. For this new transmissions line have to be erected. But this task is not found as simple as the State Transmission Company came across the problem of (Right of Way) RoW. To erect new transmission network, land acquisition is the major hurdle as people are unwilling to lend their land for this purpose. This problem shall be resolve by making proper communication, coordination and understanding with the people. In certain cases the possibility of laying $132 \mathrm{kV}$ cable is require to be identify. As soon as all these four substations are connected with nearby other substations, the problem of entire darkening shall be overcome. The tying of substations is illustrated in Fig. 3a.

Solution 2: Strengthen the Parallel Link

The parallel link is connected to the $132 \mathrm{kV}$ bus of BTPSMuktai Nagar-Bodwad-Malkapur-Khadka and back to
BTPS substations as shown in Fig. 3b. This link is unable to supply load demand more than $520 \mathrm{~A}$ at $40{ }^{\circ} \mathrm{C}$ due to constraints of conductor size i.e. 0.2 ACSR panther conductor. This is an existing corridor and it normally draw 300 A from BTPS bus at power factor about 0.98. Possibility for the application of FACT device is also determined. But due to thermal constraints of the line conductor, this possibility gets vanish. The capacity of this parallel link can be enhanced by replacing the existing conductor by 0.4 ACSR Deer conductor. But this rise the capacity just by $300 \mathrm{~A}$ and pushing $300 \mathrm{~A}$ from $400 \mathrm{kV}$ RS, Khadka to BTPS bus by this parallel link might be difficult as load on another substations in this ring can hamper this power flow. Therefore, this solution is not recommended.

Solution 3: Additional Link from $400 \mathrm{kV}$ RS Khadka and/or Increase in LTS Relay Settings

It is observed from the above case studies that, in case of strong generation dip or loss of generation, the source available is from $400 \mathrm{kV}$ RS, Khadka. There are two circuits emanating from $132 \mathrm{kV}$ Khadka bus for BTPS bus. Each circuit has CT ratio of 800/1 A and current carrying capacity up to $806 \mathrm{~A}$ at ambient temperature of $40^{\circ} \mathrm{C}$. LTS relay is set for $75 \%$ and thus the power flow of each circuit is restricted to $600 \mathrm{~A}$ for each circuit. It is strongly recommended that under the existing position, the LTS relay settings must be enhanced to $100 \%$ from $75 \%$, so that additional $400 \mathrm{~A}$ can be available in case of generation dip up to this extent. An additional circuit from $400 \mathrm{kV}$ RS, Khadka to BTPS of 0.4 ACSR deer conductor can eliminate this problem as additional 800 A flow can be available at a glance after the generation or line loss. It is observed that $132 \mathrm{kV}$ additional bay is available at BTPS but at Khadka station no space is available for the erection of new bay and RoW will also be another problem for line erection.

This problem can be resolve if the $132 \mathrm{kV}$ Malkapur feeder emanate from BTPS in spite of Khadka end. The existing Malkapur feeder should terminate at BTPS and new feeder for Malkapur shall emanate from BTPS. This is definitely a concrete solution and one spare bay is available at BTPS. It is observed that there is a problem of diversion of transmission line, this problem can be overcome by making provision of $132 \mathrm{kV}$ power cable. In our opinion this is more suitable and inexpensive solution. This solution is illustrated in Fig. 3c. The dash lines illustrate the proposed modifications. Applications of FACT devices are also studied. The thermal rating of existing 0.4 ACSR Deer conductor is the major constraint and hence it is not recommended to provide FACT device to this short transmission line. 
Fig. 3 Comprehensive solution for the effective operation of LTS of BTPS. a Tying of radial substations and load diversion, b strengthen the parallel link and $\mathbf{c}$ additional link from 400 kV RS Khadka

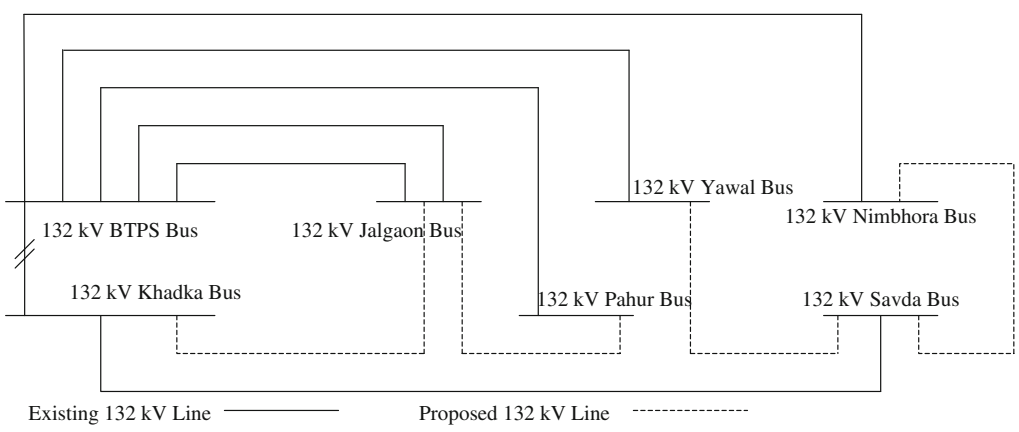

(a)

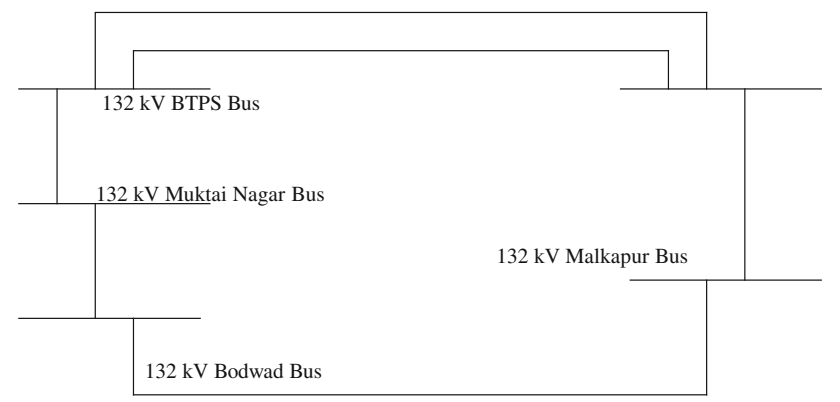

(b)

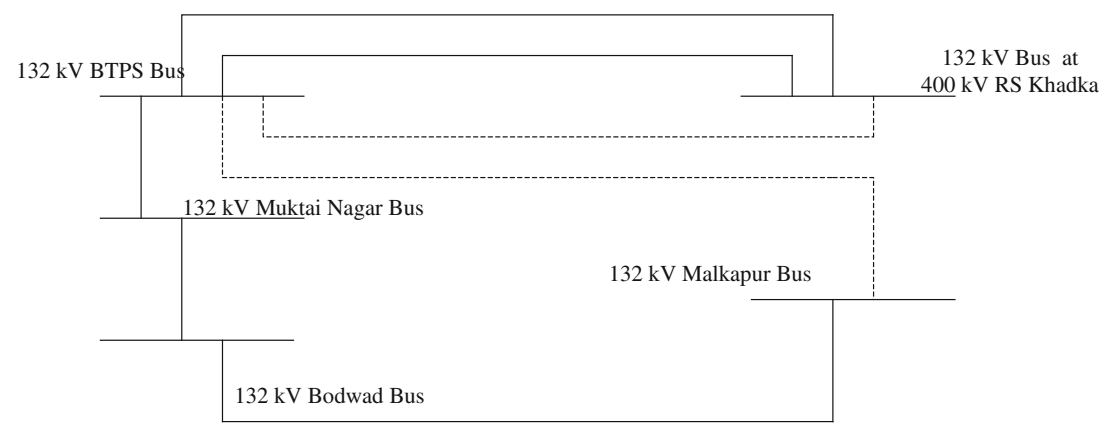

(c)
Solution 4: Development and Testing of Multi Stage Over Current Relaying Scheme

It is observed from the above discussed case studies that, for the deficiency of $50 \mathrm{~A}$, the LTS was operated. If instead of providing tripping commands to all the four radial feeders, it might be possible that any one or two feeders could be tripped. The maximum load of Jalgaon 1 and 2 is always $300 \mathrm{~A}$ each and these are twin feeders. If anyone feeder trip, another feeder always trips due over load. The maximum load of Yawal and Nimbhora feeders recorded was 400 and 200 A respectively. Jalgaon 1 and 2 are urban and industrial feeders, however, Yawal and Nibhora are rural and agricultural feeders, therefore it is recommended that the Jalgaon 1 and 2 should be given priority so that their tripping shall be avoided for the considerable short fall. Making study of all the above cases, it is strongly recommended to procure multi stage over current relay for the effective operation of LTS. The existing simple over current relay shall be replaced by this relay. The circuit connection diagram for this proposed multi stage over current relay is depicted in Fig. 4a. The GUs are also considered in addition to feeders from $400 \mathrm{kV}$, RS, Khadka. Depending upon the availability of power at BTPS bus, the multistage relay should take decision about tripping of relevant feeders. The $\mathrm{CT}$ ratios and ratios of interposing $\mathrm{CT}$ s are not mentioned to avoid complexity of the circuit. The necessary algorithm is illustrated in Fig. 4b.

The investigation is made for the setting of this proposed multistage over current relay by considering certain possible cases as tabulated in Table 3 . It is observed, in case 1 , both the lines and GUs are in service, if one GUs become off, then the deficiency raised to $700 \mathrm{~A}$. This deficiency 


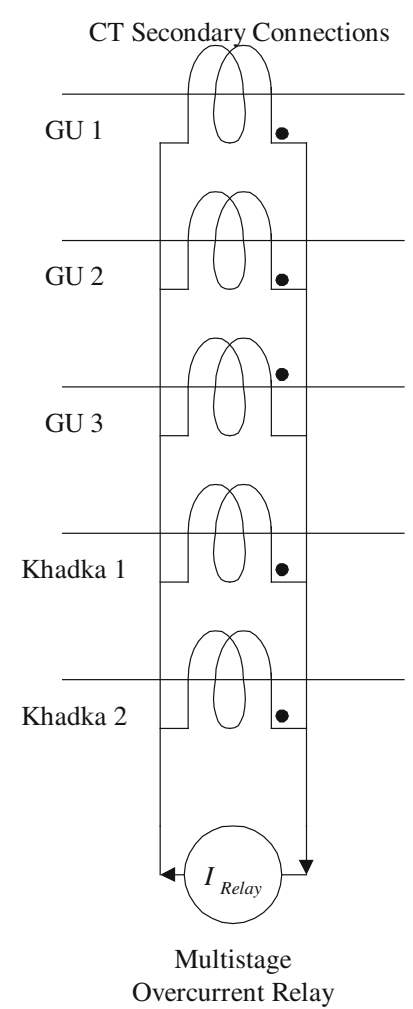

(a)

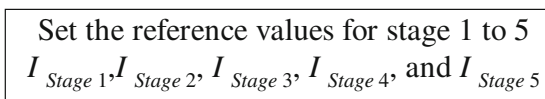

$$
I_{\text {Stage } 1}^{1}, I_{\text {Stage 2 }}, I_{\text {Stage } 2}, I_{\text {Stage } 4} \text {, and } I_{\text {Stage } 5}
$$

Check the relay current continoously $I_{\text {Relay }}$

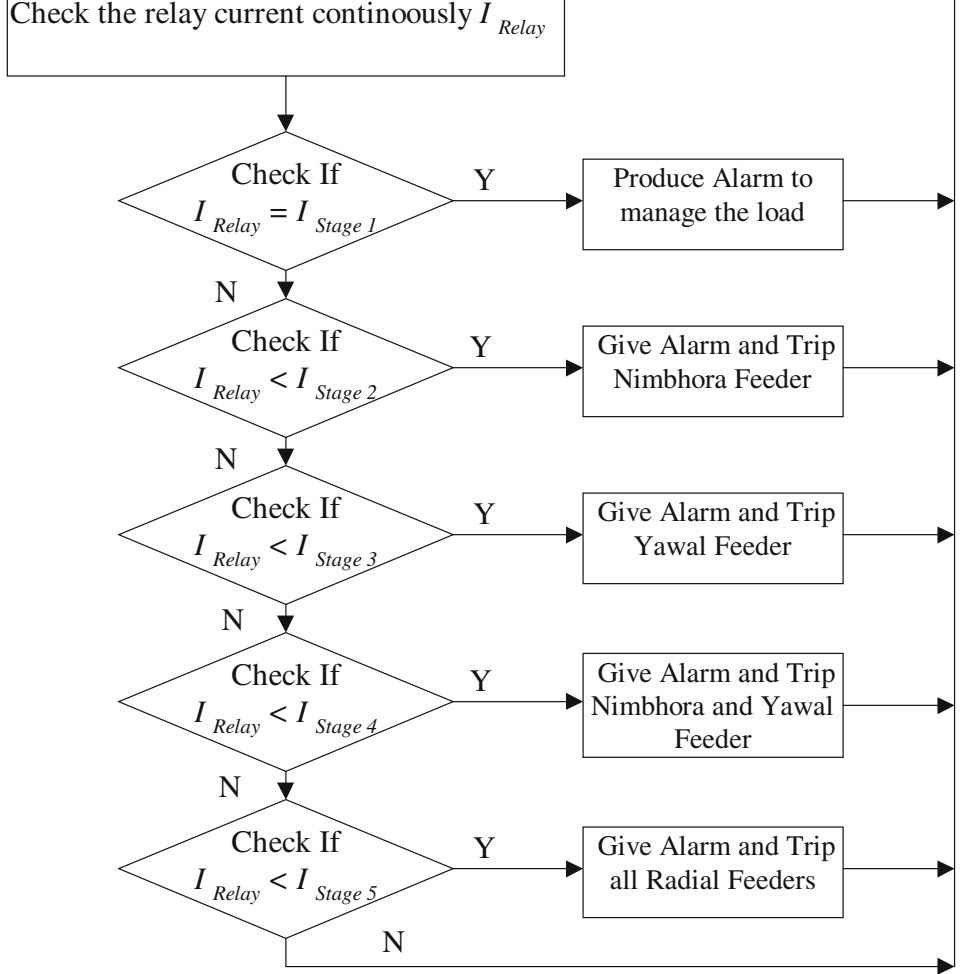

(b)

Fig. 4 a The circuit connection diagram for this proposed multi stage over current relay and $\mathbf{b}$ the algorithm for multistage relay

\begin{tabular}{|c|c|c|c|c|c|c|c|c|}
\hline \multirow[t]{2}{*}{ S1. No. } & \multirow{2}{*}{$\begin{array}{l}\text { GU in } \\
\text { service }\end{array}$} & \multirow{2}{*}{$\begin{array}{l}\text { Lines in } \\
\text { service }\end{array}$} & \multirow{2}{*}{$\begin{array}{l}\text { GU } \\
\text { become off }\end{array}$} & \multirow{2}{*}{$\begin{array}{l}\text { Line } \\
\text { become off }\end{array}$} & \multirow{2}{*}{$\begin{array}{l}\text { Deficiency } \\
\text { or shortfall }\end{array}$} & \multicolumn{2}{|c|}{ Rise in Current of import feeders } & \multirow[t]{2}{*}{ Remarks } \\
\hline & & & & & & Khadka 1 & Khadka 2 & \\
\hline 1 & 2 & 2 & 1 & 0 & 0 & $300+350$ & $300+350$ & $\begin{array}{l}\text { Rise in line load. Alarming condition } \\
\text { to monitor the load }\end{array}$ \\
\hline 2 & 2 & 2 & 0 & 1 & 0 & $300+300$ & - & $\begin{array}{l}\text { Rise in line load. Alarming condition } \\
\text { to monitor the load }\end{array}$ \\
\hline 3 & 2 & 1 & 1 & 0 & 500 & $600+200$ & - & Trip Yawal and Nimbhora feeders \\
\hline 4 & 2 & 1 & 0 & 1 & 600 & - & - & Trip Yawal and Nimbhora feeders \\
\hline 5 & 1 & 2 & 1 & 0 & 400 & $650+150$ & $650+150$ & Trip Yawal feeder only \\
\hline 6 & 1 & 2 & 0 & 1 & 500 & $650+150$ & - & Trip Yawal and Nimbhora feeders \\
\hline 7 & 2 & 0 & 1 & 0 & $600+700$ & - & - & $\begin{array}{l}\text { Manage the load and if GU trip, trip } \\
\text { all radial feeders }\end{array}$ \\
\hline 8 & 0 & 2 & 0 & 1 & $400+800$ & 800 & - & $\begin{array}{l}\text { Manage the load and if GU trip, trip } \\
\text { all radial feeders }\end{array}$ \\
\hline 9 & 2 & 2 & $1 / 2^{\mathrm{a}}$ & 0 & 0 & $300+175$ & $300+175$ & $\begin{array}{l}\text { Rise in line load. Alarming condition } \\
\text { to monitor the load }\end{array}$ \\
\hline 10 & 2 & 2 & $(1 / 2+1 / 2)^{b}$ & 0 & 0 & $300+350$ & $300+350$ & $\begin{array}{l}\text { Rise in line load. Alarming condition } \\
\text { to monitor the load }\end{array}$ \\
\hline
\end{tabular}

Table 3 Different conditions to analyse the performance of proposed multistage over-current relay

${ }^{a}$ Generation of either GU 1 or 2 drops to $50 \%$

b Generation of both GU 1 and 2 drops to $50 \%$ 
Table 4 Plug setting of proposed multistage over-current relay

\begin{tabular}{lllll}
\hline S1. No. BTPS & $\begin{array}{l}\text { Stages of } \\
\text { bus import } \\
\text { current (A) }\end{array}$ & $\begin{array}{l}\text { LTS over } \\
\text { current relay }\end{array}$ & $\begin{array}{l}\text { Setting } \\
\text { of relay (\%) }\end{array}$ & Remark \\
\hline 1 & 1,950 & $\mathrm{~S}_{1}$ & 65 & $\begin{array}{c}\text { Provide alarm to } \\
\text { manage load } \\
\text { Trip Nimbhora } \\
\text { feeder only }\end{array}$ \\
3 & 1,800 & $\mathrm{~S}_{2}$ & 60 & $\begin{array}{c}\text { Trip Yawal } \\
\text { feeder only }\end{array}$ \\
4 & 1,620 & $\mathrm{~S}_{3}$ & 54 & $\begin{array}{c}\text { Trip Yawal and } \\
\text { Nimbhora feeders } \\
\text { both }\end{array}$ \\
& 1,410 & $\mathrm{~S}_{4}$ & 47 & $\begin{array}{c}\text { Trip all radial } \\
\text { feeders }\end{array}$ \\
\hline & & & $>47$ &
\end{tabular}

shall be fulfilled by the feeders emanating from $400 \mathrm{kV}$, RS, Khadka by sharing $350 \mathrm{~A}$ in each circuit. In case 3 , two GU s and one line is in service and the GU sharing $700 \mathrm{~A}$, suddenly taken out from system, thus the load sharing from Khadka 1 raise by $200 \mathrm{~A}$ and shortfall of $500 \mathrm{~A}$ still exist. Under this circumstance, both Yawal and Nimbhora feeders shall be tripped.

In case 5, it is observed that, one $\mathrm{GU}$ and two lines are in service and suddenly the GU is withdrawal from the system, the load on each import circuit raised by $150 \mathrm{~A}$ but for the shortfall of $400 \mathrm{~A}$, it is essential to trip only Yawal feeder. The dropdown in generation of GUs is also considered in case 9 and 10. In case 9, generation of either of
GU 1 or 2 falls down by $50 \%$ and it imports $350 \mathrm{~A}$ inspite of $700 \mathrm{~A}$. Whereas, in case 10 , generation of both the GU s falls to $50 \%$ and each GU import $350 \mathrm{~A}$ inspite of $700 \mathrm{~A}$. In both the cases, there will be a significant rise in import from $400 \mathrm{kV}$, RS, Khadka but LTS will not be operated. Numbers of such combinations related to availability of GUs, lines and drop generation of individual GU $s$ are studied in this article.

Based upon the above proposed connection diagram and these eight cases, it is recommended to provide settings for this multistage relay as mentioned in Table 4 . The software program is developed in MATLAB for this effective LTS and its results for the above all condition are presented in Fig. 5a. From the simulation results, it came to know that the over current relaying system functions effectively in these five stages. The performance is tested with the simulated and actual data and it results are depicted in Fig. 5b. This system provides optimized results under the existing constraints by avoiding undesired tripping and useful to maintain the healthy supply.

The above realistic and simulated load flow case studies along with the solutions, emphasis the authors to enlist the following outcome of this article.

1. The existing setting of two lines from $400 \mathrm{kV} \mathrm{RS}$; Khadka should be raised to $100 \%$ from existing $75 \%$ and efforts should be made to tie up the radial substations with nearby sub stations.

2. Additional circuit from $400 \mathrm{kV}$ RS; Khadka should be developed either by transmission line or $132 \mathrm{kV}$ power cable. The existing Malkapur feeder should terminate

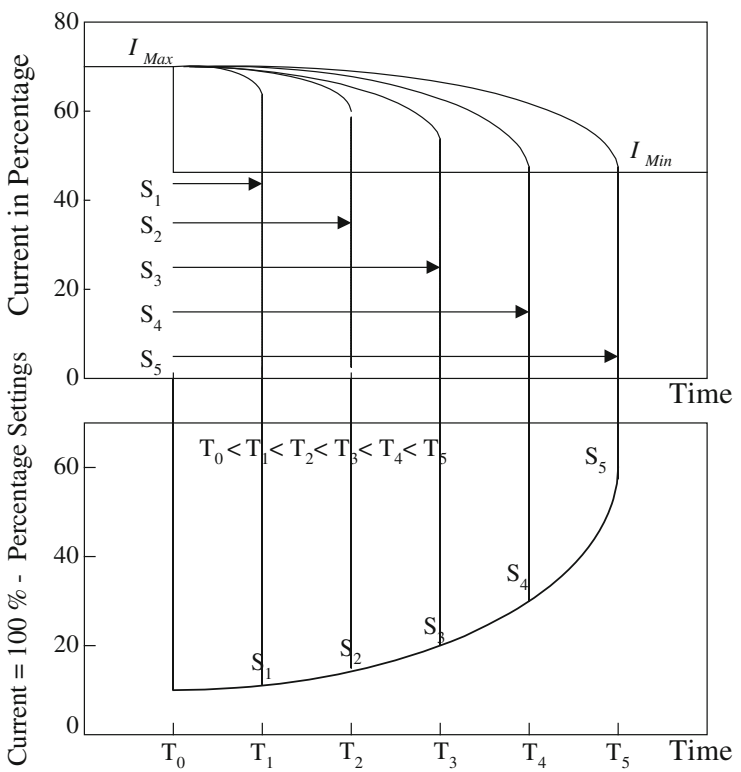

(a)

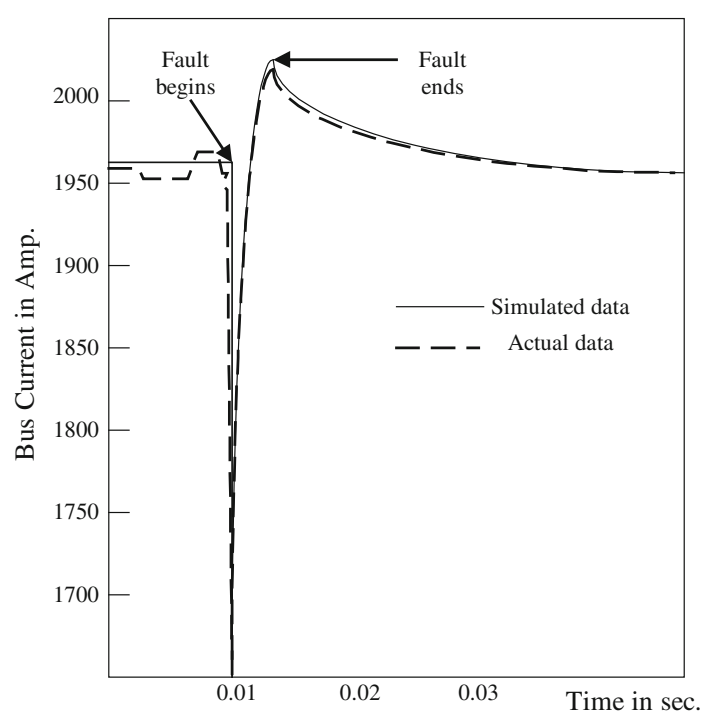

(b)

Fig. 5 a Design output of multistage relay for effective operation of LTS and b performance test results of simulated data and actual data when GU 1 suddenly taken out from system 
at BTPS and new feeder for Malkapur shall emanate from BTPS.

3. Application of FACT devices for strengthening existing parallel link or feeders from $400 \mathrm{kV} \mathrm{RS}$; Khadka did not provide concrete solution to avoid undesirable tripping due to LTS operation.

4. Application of multi stage over current relay with its connection diagram is able to provide the effective solution to optimum level.

\section{Conclusions}

This paper investigates existing load flow scenarios of a BTPS bus under various disturbance conditions and performance is evaluated by examine the load flow studies in MATLAB Simulink. The undesired tripping and thereby curtailments of important load is also described due to old GUs in power plants and inadequate capacity of transmission lines. Case studies are discussed to elaborate the critical situation of this substation under shortfall of power supply. In comparison of recorded meter data from BTPS and simulation results with and without disturbance, the deviations in the parameters are found to be acceptable. Efforts are made to strengthen the power system by proposing solutions and development of control system structure in the form of software for multistage relay. The results in respect of multistage over current relaying scheme are depicted with simulated and actual data and it validates the performance under occurrence condition in a satisfactory manner.

\section{References}

1. H. You, V. Vittal, X. Wang, Slow coherency-based islanding. IEEE Trans. Power Syst. 19(1), 483-491 (2004)

2. F. Katiraei, M.R. Iravani, P.W. Lehn, Micro-grid autonomous operation during and subsequent to islanding process. IEEE Trans. Power Deliv. 20(1), 248-257 (2005)

3. L. Yunwei, D. Mahinda Vilathgamuwa, P.C. Loh, Microgrid power quality enhancement using a three-phase four-wire gridinterfacing compensator. IEEE Trans. Ind. Appl. 41(6), 17071719 (2005)

4. L. Yun Wei, D. Mahinda Vilathgamuwa, P.C. Loh, A gridinterfacing power quality compensator for three-phase three-wire micro grid applications. IEEE Trans. Power Electron. 21(4), 1021-1031 (2006)
5. M. Prodanovi'c, T.C. Green, High-quality power generation through distributed control of a power park micro grid. IEEE Trans. Ind. Electron. 53(5), 1471-1482 (2006)

6. P. Rodriguez, A.V. Timbus, R. Teodorescu, M. Liserre, F. Blaabjerg, Flexible active power control of distributed power generation systems during grid faults. IEEE Trans. Ind. Electron. 54 (5), 2583-2592 (2007)

7. M. Dai, M.N. Marwali, J.-W. Jung, A. Keyhani, Power flow control of a single distributed generation unit. IEEE Trans. Power Electron. 23(1), 343-352 (2008)

8. X. Lin, H. Weng, Q. Zou, P. Liu, The frequency closed-loop control strategy of islanded power systems. IEEE Trans. Power Syst. 23(2), 796-803 (2008)

9. R.R. Sawant, M.C. Chandorkar, A multifunctional four-leg gridconnected compensator. IEEE Trans. Ind. Appl. 45(1), 249-259 (2009)

10. Y. Zhou, P. Bauer, J.A. Ferreira, J. Pierik, Operation of gridconnected DFIG under unbalanced grid voltage condition. IEEE Trans. Energy Convers. 24(1), 240-246 (2009)

11. M. Rylander, W. Mack Grady, A. Arapostathis, E.J. Powers, Power electronic transient load model for use in stability studies of electric power grids. IEEE Trans. Power Syst. 25(2), 914-921 (2010)

12. Z. Wang, A. Scaglione, R.J. Thomas, Generating statistically correct random topologies for testing smart grid communication and control networks. IEEE Trans. Smart Grid 1(1), 28-39 (2010)

13. A. Molderink, V. Bakker, M.G.C. Bosman, G.J.M. Smit, Management and control of domestic smart grid technology. IEEE Trans. Smart Grid 1(2), 109-119 (2010)

14. F. Li, W. Qiao, H. Sun, H. Wan, J. Wang, Y. Xia, X. Zhao, P. Zhang, Senior "Smart transmission grid: vision and framework". IEEE Trans. Smart Grid 1(2), 168-177 (2010)

15. P. Zhang, F. Li, N. Bhatt, Next-generation monitoring, analysis, and control for the future smart control center. IEEE Trans. Smart Grid 1(2), 186-192 (2010)

16. R. Podmore, M.R. Robinson, The role of simulators for smart grid development. IEEE Trans. Smart Grid 1(2), 205-212 (2010)

17. T. Zhou, B. François, Energy management and power control of a hybrid active wind generator for distributed power generation and grid integration. IEEE Trans. Ind. Electron. 58(1), 95-104 (2011)

18. I.J. Balaguer, Q. Lei, S. Yang, U. Supatti, F.Z. Peng, Control for grid-connected and intentional islanding operations of distributed power generation. IEEE Trans. Ind. Electron. 58(1), 147-157 (2011)

19. H. Karimi, A. Yazdani, R. Iravani, Robust control of an autonomous four-wire electronically-coupled distributed generation unit. IEEE Trans. Power Deliv. 26(1), 455-466 (2011)

20. J. Carpentier, Optimal power flow. Int. J. Elect. Power Energy Syst. 1, 3-15 (1979)

21. R.A.F. Currie, G.W. Ault, C.E.T. Foote, J.R. McDonald, Active power-flow management utilising operating margins for the increased connection of distributed generation. IET Gen. Transm. Distrib. 1(1), 197-202 (2007)

22. M.J. Dolan, E.M. Davidson, G.W. Ault, J.R. McDonald, Techniques for managing power flows active distribution networks with thermal constraints, in Proceedings of CIRED 2009, June 2009 